\title{
Effects of posture on carbon dioxide responsiveness in patients with obstructive sleep apnoea
}

\author{
M Satoh, W Hida, T Chonan, S Okabe, H Miki, O Taguchi, Y Kikuchi, T Takishima
}

\begin{abstract}
Background-It is well known that upper airway resistance increases with postural change from a sitting to supine position in patients with obstructive sleep apnoea (OSA). It is not known, however, how the postural change affects the ventilatory and occlusion pressure response to hypercapnia in patients with OSA when awake.

Methods-The responses of minute ventilation (VE) and mouth pressure $0 \cdot 1$ seconds after the onset of occluded inspiration $\left(\mathbf{P}_{0.1}\right)$ to progressive hypercapnia $\left(\Delta \mathrm{VE} / \Delta \mathbf{P C O}_{2}, \Delta \mathbf{P}_{0.1} I \Delta \mathbf{P C O}_{2}\right)$ both in sitting and supine positions were measured in 20 patients with OSA. The ratio of the two $\left(\Delta \dot{V} E / \Delta P_{0.1}\right)$ was obtained as an index of breathing efficiency. The postural changes in response to carbon dioxide $\left(\mathrm{CO}_{2}\right)$ after uvulopalatopharyngoplasty (UPPP) were also compared in seven patients with OSA.
\end{abstract}

Results-There were no significant changes in the resting values of end tidal $\mathrm{PCO}_{2}, \mathbf{P}_{0.1}$, or VE between the two positions. During $\mathrm{CO}_{2}$ rebreathing, $\Delta \mathrm{VE} / \Delta \mathbf{P C O}_{2}$ did not differ between the two positions, but $\Delta \mathbf{P}_{0.1} / \Delta \mathbf{P C O}_{2}$ was significantly higher in the supine than in the sitting position (supine, mean 0.67 (SE 0.09) cm $\mathrm{H}_{2} \mathrm{O} / \mathrm{mm} \mathrm{Hg}$; sitting, mean 0.57 $(\mathrm{SE} 0.08) \mathrm{cm} \mathrm{H}_{2} \mathrm{O} / \mathrm{mm} \mathrm{Hg}$ ), and $\Delta \mathrm{VE} / \Delta \mathbf{P}_{0.1}$ decreased significantly from the sitting to the supine position (sitting, $4.6(0.4)$ $1 / \mathrm{min} / \mathrm{cm} \mathrm{H} \mathrm{H}_{2} \mathrm{O}$; supine, $3.9(0.4) 1 / \mathrm{min} / \mathrm{cm}$ $\left.\mathrm{H}_{2} \mathrm{O}\right)$. In seven patients with OSA who underwent UPPP, $\Delta \dot{V} E / \Delta \mathbf{P}_{0.1}$ improved significantly in the supine position and postural change in $\Delta \dot{V} E / \Delta \mathbf{P}_{0.1}$ was eliminated.

Conclusions-These results suggest that in patients with OSA the inspiratory drive in the supine position increases to maintain the same level of ventilation as in the sitting position, and that the postural change from sitting to supine reduces breathing efficiency. Load compensation mechanisms of patients with OSA appear to be intact while awake in response to the rise in upper airway resistance.

(Thorax 1993:48;537-541)
Patients with obstructive sleep apnoea (OSA) have higher upper airway resistance than normal subjects ${ }^{12}$ and show decreased pharyngeal size and an increase in upper airway resistance on postural change from sitting to supine positions, even while awake. ${ }^{13-5}$ Moreover, the ratio of the forced expiratory flow to the forced inspiratory flow at mid vital capacity as an index of upper airway obstruction ${ }^{6}$ increases in the supine position compared with the sitting position in these patients, ${ }^{7}$ which suggests that they may have greater resistive loading in the supine than in the sitting position. Rajagopal et $a^{8}$ studied the response of ventilation and occlusion pressure to hypercapnia without and with the application of a flow resistive load in patients with OSA and found that the level of ability to compensate for the externally added inspiratory loads was impaired. We therefore hypothesise that the respiratory neuromuscular drive to hypercapnia in patients with OSA may not increase despite an increase of respiratory impedance in the supine position compared with the sitting position. It is not known, however, how postural change affects the ventilatory and occlusion pressure responses to hypercapnia in such patients while awake.

The purpose of this study was to examine postural effects on the respiratory response to hypercapnia and to compare these with postural changes in response to hypercapnia after uvulopalatopharyngoplasty (UPPP) in patients with OSA.

\section{Methods}

\section{SUBJECTS AND SLEEP STUDIES}

The study was carried out in 20 patients (19 men, one woman) with OSA previously diagnosed by polysomnography according to the definitions proposed by Guilleminault and coworkers. ${ }^{9}$ All patients had a history of snoring and complained of excessive daytime sleepiness. Eight patients complained of morning headache. They were free of complications such as lung disease or heart failure, but the one female patient had rheumatoid arthritis. The anthropometric data, spirometry, blood gas measurements, haemoglobin concentrations, and polysomnographic data of the patients are shown in table 1.

Vital capacity (VC) and forced expiratory volume in one second $\left(\mathrm{FEV}_{1}\right)$ were measured

Received 12 May 1992

Returned to authors

Revised version received

27 October 1992

Accepted 26 November 1992 
Table 1 Characteristics of 20 patients with obstructive sleep apnoea

\begin{tabular}{lc}
\hline Variables & Mean (SD) \\
\hline Age (years) & $45(9 \cdot 6)$ \\
Height (cm) & $166(5 \cdot 8)$ \\
Weight (kg) & $77(13 \cdot 0)$ \\
VC (\% pred) & $104(14 \cdot 6)$ \\
$\mathrm{FEV} / \mathrm{FVC} \mathrm{( \% )}$ & $80(6 \cdot 4)$ \\
pH & $7 \cdot 40(0 \cdot 05)$ \\
$\mathrm{PaO}_{2}(\mathrm{~mm} \mathrm{Hg})$ & $77 \cdot 3(9 \cdot 1)$ \\
$\mathrm{PaCO}_{2}(\mathrm{~mm} \mathrm{Hg})$ & $39 \cdot 1(3 \cdot 6)$ \\
$\mathrm{Haemoglobin}$ concentration (g/dl) & $15 \cdot 8(2 \cdot 0)$ \\
Apnoea index (episodes/hour) & $56 \cdot 2(16 \cdot 9)$ \\
Longest apnoea duration (s) & $82 \cdot 4(31 \cdot 4)$ \\
Lowest SaO & during sleep (\%) \\
\hline
\end{tabular}

VC - slow vital capacity; $\mathrm{FEV}_{1}$ - forced expiratory volume in one second; FVC-forced vital capacity; $\mathrm{PaO}_{2}$-arterial oxygen pressure; $\mathrm{PaCO}_{2}$-arterial carbon dioxide pressure.

with a 13.51 spirometer (Tatebe Seishudo Co, Tokyo, Japan), and arterial blood gas tensions and $\mathrm{pH}$ were measured with a $\mathrm{pH} / \mathrm{blood}$ gas analyser (Model 213 Instrumentation Laboratories, Lexington, USA). Spirometry and sampling of arterial blood from the radial artery were performed in the sitting position. Overnight sleep studies were recorded in a quiet darkened room using standard polysomnographic techniques including recording of electroencephalograms $\left(\mathrm{C}_{4} / \mathrm{A}_{1}\right.$; $\mathrm{C}_{3} / \mathrm{A}_{2}$ ), electro-oculograms, and submental electromyograms with surface electrodes to determine sleep stages. ${ }^{10}$ Air flow at the nose and mouth was recorded with two thermistors and respiratory effort was assessed with an inductive plethysmograph (Respitrace; Ambulatory Monitoring Inc., Ardsky, New York, USA) at the level of the mid thorax and umbilicus. Oxygen saturation was measured continuously with a pulse oximeter (Biox 3700; Ohmeda, Boulder, Colorado, USA). All variables were recorded with an eight channel thermal pen recorder (Model 360; NEC Sanei, Tokyo, Japan) and a data recorder (A109; Sony, Tokyo, Japan).

Written informed consent was obtained from each subject before the start of the study, which was approved by the institution's committee on human research.

\section{MEASUREMENTS OF PULMONARY AND UPPER AIRWAY FUNCTION}

Resting values of breathing frequency $(f)$, tidal volume $(\mathrm{VT})$ and minute ventilation $(\mathrm{VE})$ were measured with the spirometer.

In 16 subjects forced inspiratory and expiratory flow-volume curves were measured with a direct pen writing recorder (OST-70D Chest, Tokyo, Japan). ${ }^{11}$ Three reproducible flow-volume curves were obtained in each patient and the highest values for both the forced expiratory and inspiratory flows at mid vital capacity $\left(\mathrm{FEF}_{50}\right.$ and $\mathrm{FIF}_{50}$, respectively) were calculated. The ratio of $\mathrm{FEF}_{50}$ to $\mathrm{FIF}_{50}$ $\left(\mathrm{FEF}_{50} / \mathrm{FIF}_{50}\right)$ was also adopted as an index of extrathoracic airway obstruction. ${ }^{6}$ Patients were coached to avoid neck flexion and extension and to perform maximal expiratory and inspiratory effort in the two postures.

\section{$\mathrm{CO}_{2}$ RESPONSIVENESS AND BREATHING}

\section{EFFICIENCY}

Respiratory response to hyperoxic hypercapnia was measured by the technique of Read ${ }^{12}$ four times in each subject, twice while seated and twice while supine, using a circuit previously described..$^{1314}$ The order of assumed postures was randomised. The subject wore a noseclip and breathed through a mouthpiece connected to a rebreathing circuit. A low dead space two way valve (Model 1900, Hans Rudolph, Kansas City, Missouri, USA) was attached to the mouthpiece. The inspiratory side of the two way valve was connected to a solenoid valve, three way tap, and the rebreathing bag which contained a constant amount (VC+1 litre) of $7 \% \mathrm{CO}_{2}$ in $\mathrm{O}_{2}$. The expiratory side of the two way valve was connected to a Fleisch pneumotachograph (No 3), another three way tap, and the rebreathing bag. Air flow was measured with the pneumotachograph and a differential pressure transducer (Validyne $\mathrm{MP} 45 \pm 5 \mathrm{~cm} \quad \mathrm{H}_{2} \mathrm{O}$; Validyne Corporation, Northrige, California, USA). Tidal volume was obtained by electrical integration of the expiratory flow signal and $\dot{V E}$ was derived from multiplying the accumulation of 10 seconds of tidal breathing by six. End tidal $\mathrm{PCO}_{2}$ and $\mathrm{Po}_{2}$ were continuously monitored at the mouthpiece with a mass spectrometer (WSMR-1400; Westron, Chiba, Japan). Mouth pressure was measured at the mouthpiece using a pressure transducer (Validyne $\mathrm{MP45} \pm 50 \mathrm{~cm} \mathrm{H}_{2} \mathrm{O}$ ). Mouth pressure $0.1 \mathrm{~s}$ after the onset of an occluded inspiration $\left(\mathbf{P}_{0.1}\right)$ was measured with a system previously reported..$^{13} 14$ Occlusion of the solenoid valve was controlled manually by a logic circuit and the valve was occluded once every two to five breaths. Occlusion was induced during the preceding expiration to ensure that the airway was completely occluded at the onset of inspiration. The valve was automatically opened after the first $120 \mathrm{~ms}$ of occluded inspiration. The onset of inspiration and expiration was detected electronically by changes in mouth pressure. Circuit resistance was 0.9 $\mathrm{cm} \mathrm{H}_{2} \mathrm{O} / \mathrm{l} / \mathrm{s}$ and linear to $3 \mathrm{l} / \mathrm{s}$. Both responses of $\dot{V E}$ and $\mathrm{P}_{0.1}$ to the increase in $\mathrm{PCO}_{2}$ were analysed by linear regression. ${ }^{12-14}$ In calculating the regression lines the values of $\dot{V E}, P_{0.1}$, and end tidal $\mathrm{PCO}_{2}$ were averaged every 30 seconds during rebreathing. We obtained the slope of the ventilatory response to hypercapnia $\left(\Delta \dot{\mathrm{VE}} / \Delta \mathrm{PCO}_{2}\right)$, the slope of the occlusion pressure response to hypercapnia $\left(\Delta \mathrm{P}_{0 \cdot 1} /\right.$ $\left.\Delta \mathrm{PCO}_{2}\right)$ from each regression line, and the ratio of $\Delta \dot{\mathrm{VE}} / \Delta \mathrm{PCO}_{2}$ to $\Delta \mathrm{P}_{0.1} / \Delta \mathrm{PCO}_{2}$ $\left(\Delta \dot{\mathbf{V E}} / \Delta \mathbf{P}_{0 \cdot 1}\right)$. This ratio indicated the increase in ventilation obtained by a given increase in neuromuscular output and was defined as the breathing efficiency during hyperventilation. ${ }^{13}$ Moreover, we obtained $V E$ and $P_{0.1}$ at the $\mathrm{PCO}_{2}$ of $60 \mathrm{~mm} \mathrm{Hg}$ from the regression line by interpolation. Mean values from two regression lines were accepted for individual data.

In the measurement of pulmonary function and ventilatory response to hypercapnia, patients were coached to avoid volume leaks at the mouthpiece and care was taken to keep 


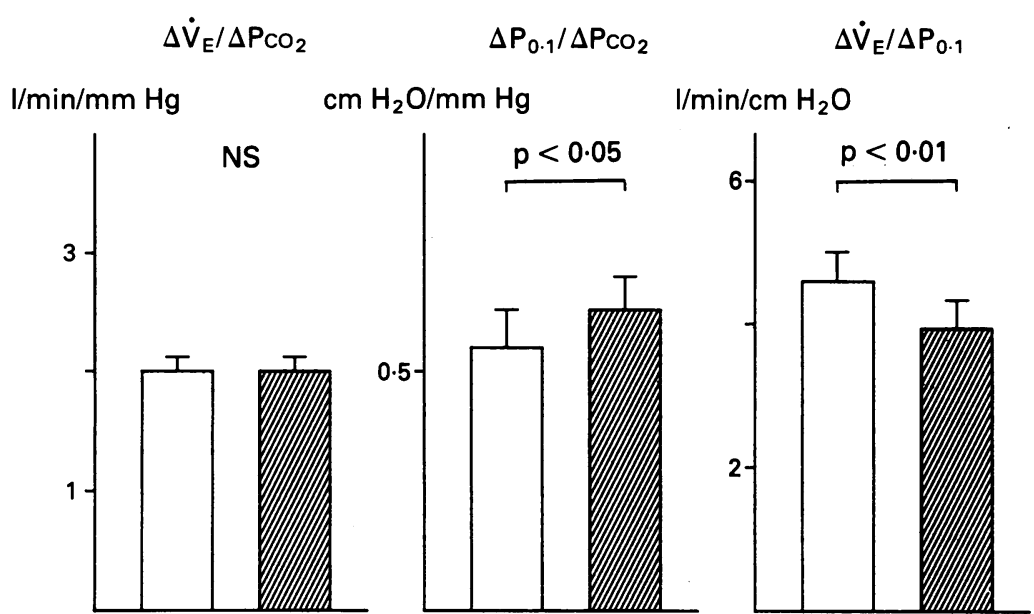

Figure 1 Mean (SE) effects of postural change on the responses of $V E\left(\Delta V E / \Delta P C O_{2}\right.$, left) and $P_{0.1}\left(\Delta P_{0.1} / \Delta P_{C O}\right.$, middle) to hypercapnia, and breathing efficiency $\left(\Delta V E / \Delta P_{0.1}\right.$, right) in 20 patients. Open bars, sitting; hatched bars, supine.

the head, neck, and trunk configuration as constant as possible between the two postures. For each study the height of the rebreathing circuit was adjusted to allow subjects to breathe through the mouthpiece without altering posture.

\section{STUDIES AFTER UPPP}

Seven patients who had complained of excessive daytime sleepiness, severe snoring, and morning headache, had severe episodes of apnoea and severe desaturation and underwent UPPP ${ }^{15}$ for treatment of OSA, were retested 2-6 months after surgery.

STATISTICAL ANALYSIS

Matched paired data within groups were compared by the Wilcoxon signed rank test. Values of $p<0.05$ were considered significant (two tailed test). Data are expressed as means (SE).

\section{Results}

Figure 1 shows the mean data of $\mathrm{CO}_{2}$ responsiveness and breathing efficiency in sitting and supine positions in 20 patients. VE response to hypercapnia was similar in the two positions (sitting, mean $2 \cdot 1$ (SE 0.2) $1 / \mathrm{min} / \mathrm{mm} \mathrm{Hg}$; supine, mean $2 \cdot 1$ (SE $0 \cdot 2$ ) $1 / \mathrm{min} / \mathrm{mm} \mathrm{Hg}$ ), but the $P_{0.1}$ response to hypercapnia was significantly higher in the supine than in the sitting position (supine, 0.67 (0.09) $\mathrm{cm} \mathrm{H} \mathrm{H}_{2} \mathrm{O} / \mathrm{mm} \mathrm{Hg}$; sitting, 0.57 (0.08) $\left.\mathrm{cm} \mathrm{H}_{2} \mathrm{O} / \mathrm{mm} \mathrm{Hg}, \mathrm{p}<0.05\right)$. Breathing efficiency $\left(\Delta \dot{V} E / \Delta \mathbf{P}_{0 \cdot 1}\right)$ decreased significantly from the

Table 2 Comparison of mean (SE) resting respiratory variables in the sitting and supine postures in 20 patients with obstructive sleep apnoea

\begin{tabular}{llll}
\hline & Sitting & Supine & Significance of difference \\
\hline $\mathrm{P}_{\mathrm{ETCO} 2}(\mathrm{~mm} \mathrm{Hg})$ & $36 \cdot 5(3 \cdot 9)$ & $37 \cdot 3(4 \cdot 0)$ & $\mathrm{NS}$ \\
$\dot{\mathrm{VE}}(1 / \mathrm{min})$ & $10 \cdot 0(2 \cdot 3)$ & $9 \cdot 3(2 \cdot 2)$ & $\mathrm{NS}$ \\
$\dot{\mathrm{VT}}(1)$ & $0 \cdot 65(0 \cdot 12)$ & $0 \cdot 62(0 \cdot 14)$ & $\mathrm{NS}$ \\
$\mathrm{f}(/ \mathrm{min})$ & $16(3 \cdot 1)$ & $15(3 \cdot 1)$ & $\mathrm{NS}$ \\
$\mathrm{P}_{0 \cdot 1}\left(\mathrm{~cm} \mathrm{H} \mathrm{H}_{2} \mathrm{O}\right)$ & $2 \cdot 4(0 \cdot 5)$ & $2 \cdot 5(0 \cdot 6)$ & $\mathrm{NS}$ \\
\hline
\end{tabular}

VE-minute ventilation; VT-tidal volume; $\mathrm{f}-$ breathing frequency; $\mathrm{P}_{0.1}-$ mouth pressure $0 \cdot 1 \mathrm{~s}$ after the onset of occluded inspiration; NS-not significant.
Table 3 Mean (SE) results of maximal expiratory and inspiratory flow-volume curve in the sitting and supine positions in 16 patients

\begin{tabular}{llll}
\hline & Sitting & Supine & $\begin{array}{l}\text { Significance } \\
\text { of difference }\end{array}$ \\
\hline FVC (1) & $4 \cdot 14(0.15)$ & $4 \cdot 12(0.14)$ & NS \\
FEF $_{50}(1 / \mathrm{min})$ & $3.79(0.31)$ & $3.67(0.30)$ & NS \\
FIF $_{50}(1 / \mathrm{min})$ & $4.30(0.30)$ & $3.90(0.25)$ & $\mathrm{p}<0.01$ \\
FEF $_{50} / \mathrm{FIF}_{50}$ & $0.88(0.04)$ & $0.94(0.05)$ & $\mathrm{p}<0.01$ \\
\hline
\end{tabular}

FVC - forced vital capacity; $\mathrm{FEF}_{50}$-forced expiratory flow at $50 \%$ of FVC; FIF $_{50}$-forced inspiratory flow at $50 \%$ of FVC; $\mathrm{FEF}_{50} / \mathrm{FIF}_{50}$-ratio of forced expiratory flow to forced inspiratory flow at mid vital capacity.

sitting to the supine position (sitting, $4.6(0 \cdot 4)$ $1 / \mathrm{min} / \mathrm{cm} \mathrm{H}_{2} \mathrm{O}$; supine, $3.9(0.4) 1 / \mathrm{min} / \mathrm{cm}$ $\left.\mathrm{H}_{2} \mathrm{O}, \mathrm{p}<0.01\right)$. As shown in fig 2 , the values of $\mathrm{VE}$ at $\mathrm{PCO}_{2}$ of $60 \mathrm{~mm} \mathrm{Hg}$ were similar in the two positions (sitting, 36.0 (2.7) $1 / \mathrm{min}$; supine, $37.5(2 \cdot 7) 1 / \mathrm{min})$, but the value of $P_{0.1}$ at $\mathrm{PCO}_{2}$ of $60 \mathrm{~mm} \mathrm{Hg}$ was significantly higher in the supine than in the sitting position (supine, $9.5(1.0) \mathrm{cm} \mathrm{H}_{2} \mathrm{O}$; sitting, $8.3(0.9)$ $\left.\mathrm{cm} \mathrm{H}_{2} \mathrm{O}, \mathrm{p}<0.05\right)$.

There were no significant changes in $\dot{V E}$, VT or $f$ between the two positions, nor for the resting values of end tidal $\mathrm{PCO}_{2}$ or $\mathrm{P}_{0.1}$ (table 2). $\mathrm{FEF}_{50}$ was also similar for the two positions but FIF $_{50}$ was smaller in the supine position. $\mathrm{FEF}_{50} / \mathrm{FIF}_{50}$ was significantly greater in the supine than in the sitting position (table 3).

In the seven patients who underwent UPPP the apnoea index decreased significantly from $56.4(2.8)$ episodes/hour to $36.0 \quad(7.9)$ episodes/hour $(p<0.05)$ and the lowest $\mathrm{SaO}_{2}$ increased from $50(6) \%$ to $63(6) \%(p<0.01)$. Following UPPP body weight decreased in five patients but increased in two; as a whole, however, there were no significant changes in body weight before and after UPPP (before UPPP, $75(1 \cdot 6) \mathrm{kg}$; after UPPP, $71(1 \cdot 4) \mathrm{kg}$ ). Table 4 shows ventilatory and occlusion pressure responses to hypercapnia in the seven patients before and after UPPP, both in the sitting and supine positions. Before UPPP, $\Delta \mathrm{P}_{0.1} / \Delta \mathrm{PCO}_{2}, \mathrm{P}_{0.1}$ at $\mathrm{PCO}_{2}$ of $60 \mathrm{~mm} \mathrm{Hg}$, and $\mathrm{FEF}_{50} / \mathrm{FIF}_{50}$ in the supine position increased

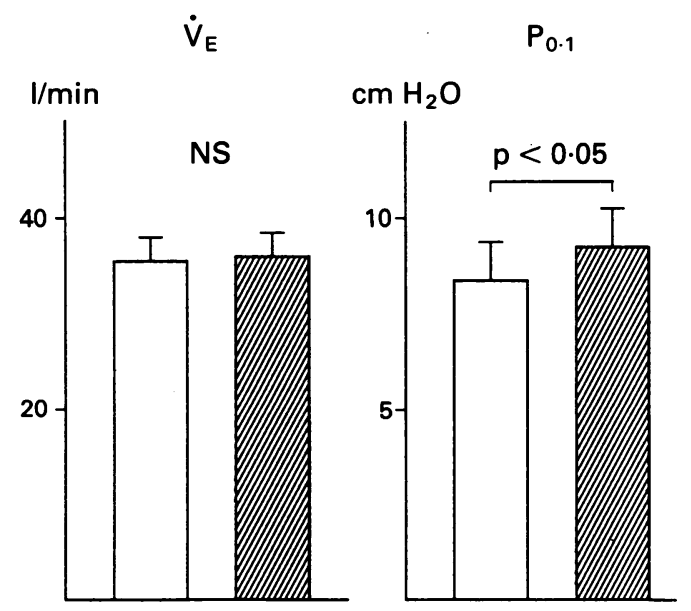

Figure 2 Mean (SE) effects of postural change on minute ventilation (VE, left) and occlusion pressure $\left(P_{\text {o.1 }}\right.$, right) at a $\mathrm{PCO}_{2}$ of $60 \mathrm{~mm} \mathrm{Hg}$ in sitting and supine positions. Open bars, sitting; hatched bars, supine. 
Table 4 Mean (SE) hypercapnic responses and maximal expiratory and inspiratory flow-volume curves in sitting and supine positions before and after UPPP in seven patients with OSA

\begin{tabular}{|c|c|c|c|c|c|c|}
\hline & \multicolumn{3}{|l|}{ Sitting } & \multicolumn{3}{|l|}{ Supine } \\
\hline & Before UPPP & After UPPP & $p^{\dagger}$ & Before UPPP & After UPPP & pt \\
\hline$\Delta \dot{\mathrm{VE}} / \Delta \mathrm{PCO}_{2}$ & $2 \cdot 3(0 \cdot 3)$ & $2 \cdot 6(0 \cdot 3)$ & NS & $2 \cdot 3(0.4)$ & $3 \cdot 1(0 \cdot 3)$ & NS \\
\hline$\Delta \mathbf{P}_{0 \cdot \mathrm{l}} / \Delta \mathbf{P C O}_{2}$ & $0.53(0.10)$ & $0.61(0.08)$ & NS & $0.71\left(0.17^{\star}\right)$ & $0.64(0.06)$ & NS \\
\hline$\Delta \mathrm{VE} / \Delta \mathrm{P}_{0.1}$ & $4.6(0.6)$ & $4.6(0.6)$ & NS & $3.8\left(0.4^{\star}\right)$ & $4.9(0.4)$ & $<0.05$ \\
\hline $\mathrm{VE}$ at $60 \mathrm{~mm} \mathrm{Hg}$ & $37 \cdot 7(4 \cdot 4)$ & $40 \cdot 5(2 \cdot 0)$ & NS & $39 \cdot 2(4 \cdot 8)$ & $45.9(3.2)$ & NS \\
\hline$P_{0.1}$ at $60 \mathrm{~mm} \mathrm{Hg}$ & $7 \cdot 5(1 \cdot 1)$ & $8.7(0.9)$ & NS & $10 \cdot 1\left(1 \cdot 3^{\star}\right)$ & $9 \cdot 1(0.8)$ & NS \\
\hline $\mathrm{FEF}_{50}(1 / \mathrm{min})$ & $4 \cdot 38(0.42)$ & $4.46(0.52)$ & NS & $4 \cdot 22(0.45)$ & $4 \cdot 20(0 \cdot 46)$ & NS \\
\hline $\mathrm{FIF}_{50}(1 / \mathrm{min})$ & $4.90(0.36)$ & $5 \cdot 17(0 \cdot 29)$ & NS & $4.36\left(0 \cdot 27^{\star}\right)$ & $4.82(0.34)$ & $<0.05$ \\
\hline $\mathrm{FEF}_{50} / \mathrm{FIF}_{50}$ & $0.88(0.05)$ & $0.86(0.09)$ & NS & $0.96\left(0.06^{\star}\right)$ & $0.81(0.08)$ & $<0.05$ \\
\hline
\end{tabular}

UPPP - uvulopalatopharyngoplasty; $\Delta \mathrm{VE} / \Delta \mathrm{PCO}_{2}$-slope of ventilatory response to hypercapnia; $\Delta \mathrm{P}_{0.1} / \Delta \mathrm{PCO}-\mathrm{slope}_{2}$ of occlusion pressure response to hypercapnia; $\Delta \dot{\mathrm{VE}} / \Delta \mathrm{P}_{0.1}$-ratio of $\Delta \mathrm{VE} / \Delta \mathrm{PCO}_{2}$ to $\Delta \mathrm{P}_{0.1} / \Delta \mathrm{PCO}_{2}$.

${ }^{\star} \mathrm{p}<0.05$ (significance between sitting and supine before or after UPPP).

tComparison before and after UPPP (significance between sitting and supine before or after UPPP).

significantly, and $\Delta \mathrm{VE} / \Delta \mathrm{P}_{0.1}$ and $\mathrm{FIF}_{50}$ in the supine position decreased significantly compared with the corresponding values in the sitting position. These findings were consistent with data obtained from all patients (figs 1,2 , and table 3 ). There were no differences in any parameters before and after UPPP in the sitting position. The differences in the supine position before UPPP were eliminated after surgery. Furthermore, after UPPP $\Delta \dot{V} E / \Delta P_{0.1}$ and $\mathrm{FIF}_{50}$ in the supine position increased significantly, and the supine $\mathrm{FEF}_{50} / \mathrm{FIF}_{50}$ fell significantly compared with the corresponding value in the supine position before UPPP.

\section{Discussion}

The study showed that the $\mathrm{VE}$ response to hypercapnia was unaffected by posture but that the $\mathrm{P}_{0.1}$ response to hypercapnia was greater in the supine than in the sitting position in patients with OSA. Furthermore, the breathing efficiency $\left(\Delta \dot{\mathrm{VE}} / \Delta \mathrm{P}_{0.1}\right)$ was less when supine than when sitting. Following UPPP there was no change in the ventilatory drive and efficiency parameters while sitting, but the breathing efficiency improved in the supine position.

There are several explanations for the increased $P_{0.1}$ responses to hypercapnia in the supine position despite the lack of the positional effect on the VE response to hypercapnia. Firstly, as the postural change from sitting to supine decreases functional residual capacity (FRC), this causes an increase in the resting length of the diaphragm ${ }^{16}$ and a shift in its force-length relationship to a more favourable position with an increase in its contractile efficiency. ${ }^{17}$ Furthermore, Xie et al ${ }^{18}$ showed that $\dot{V E}$ and diaphragmatic EMG activity responses to hypercapnia were not affected by posture. The EMG activity of the scalene muscle, however, increased to overcome the gravitational load of the thoracic cage when moving from the supine to the sitting position. Lopata et $a l^{19}$ also showed that although diaphragmatic EMG was not affected by posture at high ventilatory rates during hypercapnia, increases in the expiratory abdominal muscle activity were observed, particularly in the upright position. These two studies suggest that the respiratory control system appears to adjust the neuromuscular output to maintain the same ventilatory output between the two postures. The augmented $P_{0.1}$ response to hypercapnia found in our study may be explained by a similar adjustment of neuromuscular drive during the change in FRC associated with postural change.

Although we did not measure FRC, we could estimate changes in FRC with posture spirometrically with the assumption that residual volume was independent of posture. ${ }^{4}$ In our study the decrease in FRC was a maximum of $0.20-1.01$ (mean (SE) 0.41 $(0 \cdot 26))$ litres from the sitting to the supine position, which was within the range reported in normal subjects. ${ }^{160-22}$ It is therefore unlikely that change in FRC causes the increase in $P_{0.1}$ response to hypercapnia observed in the supine position in patients with OSA.

Although we did not directly measure upper airway resistance, it has been reported that patients with OSA have higher values than normal subjects ${ }^{12}$ and show decreased pharyngeal size and an increase in upper airway resistance on postural change, even when awake. ${ }^{13-5} \mathrm{We}$ found an increase in $\mathrm{FEF}_{50} / \mathrm{FIF}_{50}$ in the supine position which may mean that patients with OSA have greater upper airway resistance when supine. An increased $P_{0.1}$ response to hypercapnia in the supine position in patients with OSA therefore suggests an ability to compensate for the increase in upper airway resistance. This is supported by the fact that after UPPP both VE and $\mathbf{P}_{0.1}$ responses to hypercapnia were less affected by posture as has been reported in previous studies on normal subjects. ${ }^{16}{ }^{20-22}$

The elimination of postural effects on the breathing efficiency after UPPP is probably caused by a disappearance of the load compensation mechanisms associated with a decrease in upper airway resistance in the supine position following surgery. This decrease would be supported by a fall in supine $\mathrm{FEF}_{50} / \mathrm{FIF}_{50}$ together with an increase in $\mathrm{FIF}_{50}$. We therefore suggest that the load compensation mechanisms for the increase in upper airway resistance in patients with OSA before UPPP are present at least while they are awake.

It is not clear whether compensation for an 
increase in the internal loads operates equally during sleep as the measurements were all made while the subjects were awake. During sleep the upper airway muscles become more hypotonic and the airway becomes narrower both in normal subjects and in patients with OSA. ${ }^{23} 24$ Greater activation of inspiratory muscles is therefore required to maintain ventilation, but this may not occur as the load compensation ability of respiratory muscles is less during sleep than when awake. ${ }^{25-27}$ Moreover, increased activity of the inspiratory muscles without recruitment of upper airway dilating muscles could worsen upper airway obstruction. Further studies are needed to elucidate the actual load compensation of both upper airway and inspiratory muscles in response to positionally induced mass loading of the upper airway, especially during sleep.

We would like to thank Mr G Crittenden for his help in preparation of the manuscript and Drs $\mathrm{N}$ Iwase and $\mathrm{C}$ Miura for their technical assistance.

1 Anch AM, Remmers JE, Bunce $H$. Supraglottic airway resistance in normal subjects and patients with occlusive sleep apnea. 7 Appl Physiol 1982;53:1158-63.

2 Stauffer J, Zwillich CW, Cadieux RJ, Bixler EO, Kales A, Varano LA, et al. Pharyngeal size and resistance in obstructive sleep apnea. Am Rev Respir Dis 1987;136: 623-7.

3 Kryger M, Bode F, Antic R, Anthonisen N. Diagnosis of obstruction of the upper and central airways. $\mathrm{Am} \mathcal{F} \mathrm{Med}$ 1976;61:85-93.

4 Brown IB, McClean PA, Boucher R, Zamel N, Hoffstein $V$. Changes in pharyngeal cross-sectional area with posture and application of continuous positive airway pressure in patients with obstructive sleep apnea. $A m ~ R e v$ Respir Dis 1987;136:628-32.

5 Fouke JM, Strhol KP. Effect of position and lung volume on upper airway geometry. I Appl Physiol 1987;63: on upper

6 Miller RD, Hyatt RE. Evaluation of obstruction lesions of the trachea and larynx by flow-volume loops. Am Rev Respir Dis 1973;108:475-81.

7 Miura C, Hida W, Miki H, Kikuchi Y, Chonan T, Takishima $T$. Effects of posture on flow volume curves during normocapnia and hypercapnia in patients with obstructive sleep apnoea. Thorax 1992;47:524-8.

8 Rajagopal KR, Abbrechet PH, Tellis CJ. Control of breathing in obstructive sleep apnea. Chest 1984;85: 174-80.

9 Guilleminault C, Tilkian A, Dement WC. The sleep apnea syndrome. Annu Rev Med 1976;27:465-84.
10 Rechtshaffen A, Kales A, eds. A manual of standardized terminology, techniques and scoring system for sleep stages of human subjects. NIH publication No. 204. Bethesda: human subjects. NIH publication

11 Takishima T, Sasaki T, Takahashi K, Sasaki H, Nakamura T. Direct-writing recorder of the flow-volume curve and it clinical application. Chest 1972;61: 262-6.

12 Read DJC. A clinical method for assessing the ventilatory response to $\mathrm{CO}_{2}$. Australas Ann Med 1967;16:20-32.

13 Chonan T, Hida W, Kikuchi Y, Shindoh C, Takishima T. Role of $\mathrm{CO}_{2}$ responsiveness and breathing efficiency in determining exercise capacity of patients with chronic airway obstruction. Am Rev Respir Dis 1988;138: 1488-93.

14 Hida W, Suzuki R, Kikuchi Y, Shindoh T, Chonan T, Sasaki $H$, et al. Effect of local vibration on ventilatory response to hypercapnia in normal subjects. Bull Eur Physiopathol Respir 1978;23:227-32.

15 Fujita S, Conway W, Zorick F, Roth T. Surgical correction of anatomic abnormalities in obstructive sleep apnea syndrome: uvulopalatopharyngoplasty. Otolaryngol Head Neck Surg 1981;89:923-34.

16 Moreno F, Lyons $H$. Effect of body posture on lung volumes. F Appl Physiol 1961;16:27-9.

17 Braun NMT, Arora NS, Rochester DF. Force-length relationship of the normal human diaphragm. F Appl Physiol 1982;53:405-12.

18 Xie A, Takasaki Y, Popkin J, Orr D, Bradley TD. Chemical and postural influence on scalene and diaphragmatic activation in humans. $f$ Appl Physiol 1991;70:658-64.

19 Lopata M, O'Connor TD, Onal E. Effects of position on respiratory muscle function during $\mathrm{CO}_{2}$ rebreathing. Respiration 1985;47:98-106.

20 Burki NK. The effect of changes in functional residual capacity with posture on mouth occlusion pressure and ventilatory pattern. Am Rev Respir Dis 1977;116: 895-900.

21 Lederer DH, Altose MD, Kelsen SG, Cherniack NS. Comparison of occlusion pressure and ventilatory responses. Thorax 1977;32:212-20.

22 Grassino AE, Derenne JP, Almirall J, Milic-Emili J, Whitelaw $W$. Configuration of the chest wall and occlusion pressures in awake humans. $\mathcal{F}$ Appl Physiol 1981;50 $134-42$.

23 Issa FG, Sullivan CE. Upper airway closing pressures in obstructive sleep apnea. $\mathcal{F}$ Appl Physiol 1984;57:520-7.

24 Aronson RM, Onal E, Carley DW and Lopata M. Upper airway and respiratory muscle responses to continuous negative airway pressure. F Appl Physiol 1989;66: 1373-82.

25 Santiago TV, Sinha AK, Edelman NH. Respiratory flowresistive load compensation during sleep. Am Rev Respir Dis 1981;123:382-7.

26 Iber C. Berssenbrugge A, Skatrud JB, Dempsey JA. Ventilatory adaptations to resistive loading during wakefulness and non-REM sleep. $\mathcal{F}$ Appl Physiol 1982;53:607-14.

27 Hutt DA, Parisi RA, Edelman NH, Santiago TV. Responses of diaphragm and external oblique muscles to flow-resistive loads during sleep. Am Rev Respir Dis 1991;144:1107-11. 